Revista Brasileira de Geografia Física v11, n.03 (2018) 1162-1175.

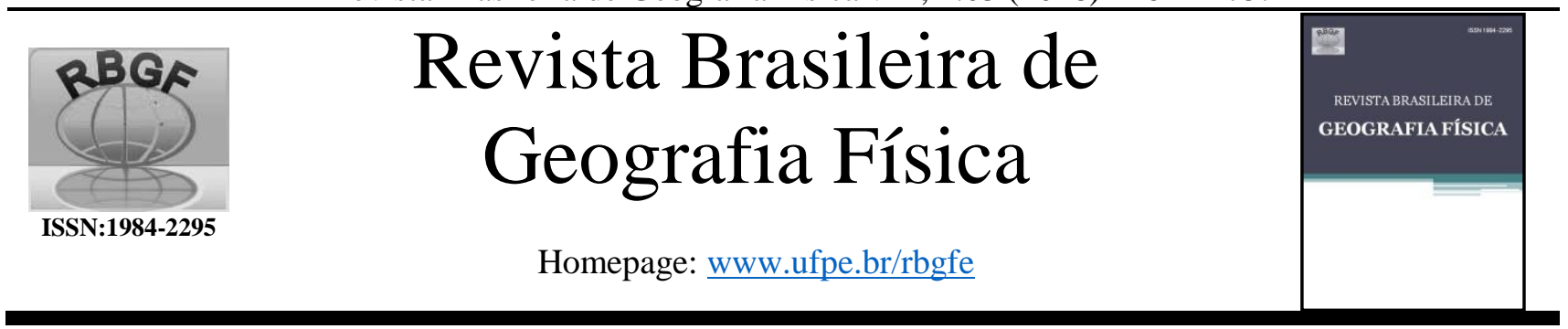

\title{
Dialética Contemporânea sobre Áreas de Preservação Permanente: Quando a Exceção a Cada vez mais é Legitimada como Regra
}

Dweison Nunes Souza da Silva. Mestre em Desenvolvimento e Meio Ambiente - PRODEMA (UFPE)

Membro do Grupo de Pesquisa Sociedade e Natureza Nexus (UFPE). Autor correspondente: E-mail: dweison.nunes@ufpe.br Edvânia Torres Aguiar Gomes. Professora Doutora Titular, Geografia, Universidade Federal de Pernambuco (UFPE). Coordenadora do Grupo de Pesquisa Sociedade e Natureza Nexus (UFPE). E-mail: torres@ufpe.br Aura Gonzalez Serna. Professora Doutora, Ciências Sociales, Universidad Pontificia Bolivariana (UPB), Colômbia. Membro dos Grupos de Pesquisa Territorio (UPB) e Sociedade e Natureza Nexus (UFPE). E-mail: aura.gonzalez@ upb.edu.co

Artigo recebido em 01/01/2018 e aceite em 20/07/2018

\section{R E S U M O}

Considerando as leis ambientais como um dos instrumentos de fundamental importância para o enfrentamento de impactos ambientais à natureza em função de atividades ligadas, em especial, à imperativos de ordem econômica e de que para a sua efetividade dependem de políticas públicas de uma maneira geral, este artigo busca analisar em que medida as leis ambientais que dispõem sobre Áreas de Preservação Permanente (APP) constituem efetividade no âmbito do Complexo industrial portuário de Suape (CIPS) - Pernambuco - Brasil, uma vez que as informações preliminares sobre o CIPS e suas atividades com sustentabilidade apresentam contradições entre a teoria concebida e suas práxis. Para tanto procedeu-se uma revisão histórica/bibliográfica acerca das leis ambientais que tratam de APPs, contextualizadas ao uso e ocupação do solo no CIPS historicamente. Observa-se que o tratamento dado a legislação ambiental que dispõe sobre APPs no território de Suape é condicionada por práxis de (des)legitimação, à medida que as políticas públicas direcionadas ao CIPS têm atuado num contexto de legitimação de leis autorizativas de ordem estritamente econômica, logo, deslegitimando ao que dispõe toda uma legislação. Fator que explica em parte os motivos pelos quais o desenvolvimento econômico é quase e/ou totalmente desarticulado da escala local. Finalmente, o comportamento sustentável apenas teleológico difundido pelos agentes públicos e privados acerca de Suape demonstra que o ideal de sustentabilidade para as atividades econômicas contemporâneas precisam ser apreendias com o rigor necessário, e ademais com suficiente exemplos práticos cujo resultado sejam práxis de regra e não de exceção.

Palavras-chave: Políticas Públicas, Leis ambientais, Desenvolvimento sustentável.

\section{Contemporary Dialectics on Areas of Permanent Preservation: When the Exception is Increasingly Legitimized as a Rule}

\section{A B S T R A C T}

Considering the environmental laws as one of the tools of fundamental importance for the confrontation of the environmental impacts to the nature in function of activities linked, in particular, the imperatives of economic order; and that for their effectiveness they depend on public policies in general, this paper aims to analyze the extent to which the environmental laws that have been applied to Permanent Preservation Areas (PPA) are being effectively fulfilled within the framework of the Suape Port Industrial Complex (SPIC) - Pernambuco - Brazil, since preliminary information on SPIC and their activities with sustainability, present contradictions between the conceived theory and its praxis. For this, a historical / bibliographic review was carried out on the environmental laws that deal with PPAs, contextualized to the use and occupation of the soil in the scope of CIPS historically. It is observed that the treatment given to environmental legislation that has PPAs in the territory of Suape has its praxis conditioned by (dis) legitimation, as the public policies directed to the SPIC have acted in a context of legitimation of authorizing laws of strictly economic order, therefore, delegitimizing the provisions of all legislation. This is 
Revista Brasileira de Geografia Física v11, n.03 (2018) 1162-1175.

a case of economic development that is almost totally disjointed from the local scale. Finally, the only teleological sustainable behavior disseminated by public and private agents about Suape demonstrates that the ideal of sustainability for contemporary economic activities needs to be apprehended with the necessary rigor, and in addition with enough practical examples whose results are praxis of rule and not of exception.

Keywords: Public Policies, Environmental Laws, Sustainable Development.

\section{Introdução}

No âmbito do poder político-administrativo brasileiro - em instâncias municipal, estadual e federal - as leis, para este estudo, orientadas à proteção dos ambientes "naturais" ameaçados (ou não) por degradações adquirem centralidade e em muitos casos condição sine qua non. Sua imprescindibilidade (leis ambientais) teórica e prática é justificada, sobretudo, em consequência de atividades humanas relacionadas ao sistema de reprodução socioeconômico basilado em crescimento (econômico) exponencial; que trivialmente tem se sociometabolizado (para citar Mészáros, 2011) à custa da exploração social e da natureza. Logo, pode-se concluir que as leis ambientais se convertem ou pelos menos deveriam torna-se uma ferramenta essencial à efetiva conservação e preservação da natureza promovendo em alguma medida ganhos à sociedade de uma maneira geral. Os escritos que sucedem essa introdução comprovam tal assertiva.

A dialética está no fato de não raramente a legitimidade das leis ambientais, em suas diferentes escalas e níveis de atuação, serem autorizadas pelas intencionalidades que lhes são dadas ${ }^{1}$, na medida em que podem servir, de um lado, para objetivar o que ao longo da história da humanidade ainda se encontram no campo teórico, e de outro, como uma forma de resistência - legitimando intentos conservacionistas e preservacionistas, por exemplo. Em razão disso é coerente e necessário colocar que o atual modelo de desenvolvimento, na contemporaneidade é a cada vez mais condicionado pela tecnociência-informacional (para citar Santos,

\footnotetext{
${ }^{1}$ Bakhtin (2010) faz várias advertências sobre o uso da palavra, ao assinalar que a depender de quem fala e das intenções explicita e implicitamente (em sua maioria), podem fazerem-nos ser e outras vezes não ser; configurando relações de dominação e de resistência. Para o caso das leis, suas prerrogativas podem apenas ficar no campo teórico e/ou ainda servir como argumento legitimador de atividades exploratórias.
}

2010). O contexto contemporâneo permite afirmar que a técnica (enquanto conhecimento) produz tecnologias, que por vezes podem ser utilizadas por agentes para fins ideológicos, como nos adverte Santos (2010) "[...] nas condições atuais, as técnicas da informação são principalmente utilizadas por um punhado de atores em função de seus objetivos particulares". Em síntese, o uso das tecnologias a fim de produzir e disseminar informações (baseados no discurso) ao serviço de legitimação de um determinado status quo.

Essas considerações sobre as leis ambientais e o uso continuado de tecnologias da informação pode ser inferida no contexto das atividades do Complexo Industrial Portuário de Suape (CIPS). Localizado no Estado de Pernambuco - Brasil e em termos de território e de influência, o CIPS se insere entre os municípios de Ipojuca e Cabo de Santo agostinho configurando-se (atual e de gênese), de um lado, como a salvação econômica para o Estado, uma vez que os seus resultados econômicos ${ }^{2}$ são relevantes aos anseios ideológicos (político-privado) adotados, próprios de sociedades de desenvolvimento econômico cuja busca por mais valia é verticalizado sempre para cima. Números valorizados e amplamente divulgados pelos agentes políticos e econômicos, em especial, pelo Estado.

De outro lado é em igual medida difundido pelo CIPS, o crescimento econômico aliado a uma densa agenda socioambiental contempladas em 7 links: Gestão Ambiental e seus 12 sub links; Saúde e Segurança com 5 sub links; Educação Ambiental com 3 sub links, Projeto de Pedagogia Ambiental; Responsabilidade Socioambiental com 4 sub links;

\footnotetext{
2 De acordo com as notícias divulgadas em outubro de 2017, as atividades oriundas do CIPS cresceram exponencialmente desde o ano de 2005, chegando ao recorde histórico no final de 2017 em movimentação de cargas totais (cerca de $400 \%$ maiores em relação a 2005) (disponível em: http://www.suape.pe.gov.br/pt/noticias/8noticias/1062-suape-registra-em-outubro-melhormovimentacao-mensal-de-sua-histori).
} 
Revista Brasileira de Geografia Física v11, n.03 (2018) 1162-1175.

Desenvolvimento com Sustentabilidade e Legislação

Ambiental, todos sob a diretoria e coordenação de 5 núcleos, que, como consta no website Suape (disponível

em:

http://www.suape.pe.gov.br/pt/meio-

ambiente/desenvolvimento-com-sustentabilidade)

coexistem e corroboram para a formação do tripé de sua sustentabilidade: o econômico, o social e o ambiental. Resultando na ampliação de $48 \%$ para $59 \%$ de áreas preservadas em relação ao seu último plano diretor, Suape 2030; pelo menos no discurso (Suape, 2011).

Crescimento econômico com sustentabilidade seria a síntese mais coerente concebida pelo e para o CIPS, considerando os dois parágrafos anteriores. Levando em conta que a vida cotidiana é por vezes diferente da teoria, a questão a ser analisada é até que ponto populações locais e a natureza constituem, na prática, prioridade nas atividades desempenhadas pelo CIPS historicamente. Essa pergunta norteadora é relevante, à medida que o CIPS é gênese e em continuum teleologicamente moldado e ampliado aos padrões do pensamento capitalista de reprodução. Sua pedra fundamental, lançada na década de 70 do século passado e efetivamente materializado na década seguinte é palco de grandes debates, especialmente, em torno dos aspectos ambientais ${ }^{3}$ e sociais. Inicialmente por conta de sua localização geográfica próximo a biomas de mata de atlântica com predominância de restingas e manguezais, além de rios e ecossistemas costeiros imprescindíveis à sustentabilidade local. De outro lado, a questão social gira em torno das muitas famílias, cerca de 22 engenhos, que obrigatoriamente foram desapropriados para a implantação do CIPS sob a égide do desenvolvimento econômico e do progresso (Gumiero, 2016); um discurso que perdura até os dias atuais.

Em que pese a questão ambiental, os ambientes "naturais" supramencionados constituem centralidade, especialmente em razão de sua importância à sustentabilidade local (para pescadores e pescadoras, local de reprodução de muitos espécimes animais e endêmico para outros espécimes

3 Movimentos ambientalistas constituídos por pesquisadores, ONGs e a sociedade civil como um todo já na época do lançamento da pedra fundamental do CIPS organizaram protestos em torno dos possíveis impactos ambientais resultantes, em especial, aos manguezais e vegetais). Não por acaso, são considerados pela legislação brasileira, Lei federal 4.771/65 e atual Lei $\mathrm{n}^{\mathrm{o}}$ 12.727/12, Áreas de Preservação Permanente, doravante APP, por sua vez conceituada de forma detalhada como (Senado Federal, 2012; Senado Federal, 2016): “Art. $3^{\circ}$ área protegida coberta ou não por vegetação nativa, com a função ambiental de preservar os recursos hídricos, a paisagem, a estabilidade geológica, a biodiversidade, o fluxo gênico de fauna e flora, proteger o solo e assegurar o bem-estar das populações humanas".

Adicionalmente, acerca dos limites e delimitações, consideram-se de preservação permanente as florestas e demais formas de vegetação natural situadas, artigo $4^{\circ}$, Lei $n^{\circ}$ $12.727 / 12$, em zonas rurais ou urbanas (Senado Federal, 2012): "I - As faixas marginais de qualquer curso d'água natural perene e intermitente, excluídos os efêmeros, desde a borda da calha do leito regular, em largura mínima de a) 30 (trinta) metros, para os cursos d'água de menos de 10 (dez) metros de largura" e "b) 50 (cinquenta) metros, para os cursos d'água que tenham de 10 (dez) a 50 (cinquenta) metros de largura"; "VI - As restingas, como fixadoras de dunas ou estabilizadoras de mangues; VII - os manguezais, em toda a sua extensão".

A mesma Lei (12651/12) assinala, em seu Art. $4^{\mathrm{a}}$, parágrafo $1^{\mathrm{o}}$, que a supressão de vegetação em APP depende de autorização do órgão ambiental estadual competente, com anuência prévia, quando couber, do órgão federal ou municipal de meio ambiente, fundamentados em parecer técnico. Contexto, obviamente legitimado e conduzido com o que determina a Constituição da República Federativa do Brasil (Brasil, 2016); em seu art. 225: "Todos têm direito ao meio ambiente ecologicamente equilibrado, bem de uso comum do povo e essencial à sadia qualidade de vida, impondose ao Poder Público e à coletividade o dever de defendê-lo e preservá-lo para as presentes e futuras gerações”. Em adição, o $\S 1^{\circ}$ assinala que para assegurar a efetividade desse direito, incumbe ao Poder Público "III - definir, em todas as unidades da Federação, espaços territoriais e seus componentes a serem especialmente protegidos, sendo a alteração e

recursos hídricos. Concebiam a alternativa de imaginar outros usos para a sua feliz dotação de beleza natural e de outros recursos para o lazer, além de ser sítio histórico do maior interesse (Cavalcanti e Rocha, 2015). 
Revista Brasileira de Geografia Física v11, n.03 (2018) 1162-1175.

a supressão permitidas somente através de lei, vedada qualquer utilização que comprometa a integridade dos atributos que justifiquem sua proteção" e finalmente "IV - Exigir, na forma da lei, para instalação de obra ou atividade potencialmente causadora de significativa degradação do meio ambiente, estudo prévio de impacto ambiental, a que se dará publicidade".

Nada obstante, para o cumprimento das responsabilidades acerca das diretrizes, criação e deliberações em âmbitos federal, estadual e municipal, o Brasil tem sua gênese na década de 80 do século passado; através da lei $\mathrm{n}^{\circ} 6.938$, de 31 de agosto de 1981 destinada a criação da Política Nacional de Meio Ambiente 4 cujos objetivos são: “i) a preservação, melhoria e recuperação da qualidade ambiental propícia à vida, no País e ii) assegurar condições ao desenvolvimento socioeconômico, aos interesses da segurança nacional e à proteção da dignidade da vida humana" (MMA, 2016).

Esta lei também cria os órgãos responsáveis pela proteção - no sentido de aplicabilidade visando a melhoria da qualidade ambiental, que juntos constituem o Sistema Nacional do Meio Ambiente - SISNAMA. Pode-se citar como exemplo, o Instituto Brasileiro do Meio Ambiente e dos Recursos Naturais Renováveis - IBAMA e o Instituto Chico Mendes de Conservação da Biodiversidade, responsáveis por executar e fazer (executar) a política e as diretrizes governamentais (denominados órgãos executores). Finalmente os órgãos seccionais como: entidades estaduais ajuizadas pela execução de programas, projetos e pelo controle e fiscalização de atividades capazes de provocar a degradação ambiental; para o caso de Pernambuco, a cargo da Agência Estadual de Meio Ambiente (CPRH) (MMA, 2016).

Uma constatação inicial é a de que na teoria não faltam mediações legais para o efetivo cumprimento do que se pede na constituição federal e em dispositivos com funções similares. Todavia, não é sempre (ao contrário disso) que a teoria se constitua na prática; em muitos casos - quer na ótica ambiental, quer na política, econômica e social -, oportunamente as práxis fazem de exceções as regras. Por exemplo, a regra geral orientada para os ambientes mencionadas pró́be notoriamente o seu

\footnotetext{
4 Por "Política Nacional do Meio Ambiente" deve-se entender normas e diretrizes que guiam o Estado brasileiro
}

uso para fins econômicos (Cavedon, Vieira e Diehl., 2011; Pinheiro et al., 2013) em virtude de sua imprescindibilidade preservacionista. Entretanto, as exceções de Interesse Social e Utilidade Pública (Senado Federal, 2012) presentes nas leis que tratam de APPs têm sido utilizadas como argumento legitimador de atividades com acentuado grau de impactos ambientais. No território de Suape, como veremos, essa prática de exceção é reiteradamente utilizada como argumento à implantação e ampliação de megaempreendimentos diversos; respaldada sob a contradição permanente dos órgãos ambientais correntes.

Nesta ótica, o presente artigo busca analisar em que medida as leis ambientais que dispõem sobre Áreas de Preservação Permanente (APP) constituem efetividade no âmbito do Complexo industrial portuário de Suape (CIPS) - Pernambuco - Brasil, uma vez que as informações preliminares sobre o CIPS e suas atividades com sustentabilidade, apresentam contradições entre a teoria concebida e suas práxis.

\section{Material e métodos}

As mediações metodológicas se iniciam com a recuperação histórica acerca das leis ambientais brasileiras dedicadas às APPs, bem como os respectivos instrumentos legais necessários à sua aplicabilidade (a política nacional de Meio Ambiente de 1981, decretos e resoluções posteriores, que instituem os órgãos com funções consultivas, deliberativas, de controle e fiscalização nos âmbitos federal, estadual, municipal e no distrito federal), contextualizados com o que dispõe a constituição federal e os imperativos socioambientais em escalas diversas.

Concomitante, se realizam análises da ocupação e uso do solo via geoprocessamento, com a utilização do software ArcGIS, considerando o que afirmam Silva e Machado (2010) ao projetarem o software como uma ferramenta importante na utilização de dados matemáticos e computacionais para o tratamento de informações geográficas, conceituadas como Sistemas de Informações Geográficas (SIG).

para a efetivação do disposto no art. 225 da Constituição Federal de 1988. (Canestrini, 2016). 
Revista Brasileira de Geografia Física v11, n.03 (2018) 1162-1175.

Nesse sentido o ArcGIS é utilizado para criação, georrefereciamento e tratamento dos mapas, e na análise das informações mapeadas sobre a área de estudo: o CIPS e o seu entrono. Adicionalmente, também se utiliza a ferramenta de Zoneamento Agroecológico do Estado de Pernambuco - ZAPE, bem como o software Google Earth Pro (Embrapa, 2017). Juntos, esses dispositivos contribuíram à análise precisa dos usos e ocupações do solo em Suape em finais da década de 80 e mais recentemente em 2008, 2010 e 2016. Simultaneamente foram realizadas visitas em campo ao CIPS e o seu entorno.

\section{Resultados e discussão}

Observa-se que implantação do CIPS e sua ampliação (com a chegada de novos empreendimentos) estão historicamente relacionados à impactos ambientais, que envolvem principalmente a supressão de manguezais e a contaminação de recursos hídricos. Logo, atuando de forma paradoxal às diretrizes constitucionais vigentes, uma vez que ambos os ambientes estão incluídos por leis federais, estaduais e municipais como APPs, cuja caracterização pressupõe a sua proteção em nível preservacionista. Em resumo, não sendo permitida a intervenção (supressões) com objetivos econômicos (Cavedon, Vieira e Diehl, 2011; Brasil, 2016); com exceção - e daí é que emergem todos os argumentos para degradações e supressões em Suape (Fórum Suape, 2017) - em casos de Utilidade pública e de Interesse Social.

Verifica-se, por exemplo, que a Utilidade Pública e o Interesse Social já iniciam um processo de inversão - ao invés de exceção, se "convertem" em regra geral - na década de 80. Os dados disponibilizados por Braga, Uchoa e Duarte. (1989), ao tratar sobre os Impactos Ambientais aos manguezais em Suape, evidenciam que em 1974 haviam em torno de 2.874 hectares de APPs nas medições de Suape. Passados quatorze anos (1988), os autores chamam a atenção para o fato de que "considerando-se apenas a área de jurisdição do Complexo Industrial e Portuário, dos 1.005 hectares de mangue existentes dentro dos seus limites, $60 \%$ já estão degradados...", afetando principalmente o "manguezal do rio Tatuoca e parcialmente nos rios Massangana e Ipojuca" (Braga, Uchoa e Duarte., 1989, p. 15)
A reflexão é a de que o Código florestal 4771/65 já se encontrava em vigor, com o nível de detalhamento satisfatório acerca do conceito, delimitações e penalidades sobre APPs, logo, não havendo a possibilidade de negligenciamento de seu cumprimento por parte do Estado. A questão gira em torno do contexto histórico no qual o CIPS emerge. A crise econômica experimentada em nível global na década de 1970, em especial as crises do petróleo, o fim do Estado keynesiano e a consequente adoção do neoliberalismo autorizam a entrada dos países centrais capitalistas nos novos territórios; uma estratégia expansionista com a consequente exploração dos recursos dos países em desenvolvimento (Paniago, 2005; Lessa, 2013).

É importante pontuar que em nível nacional, o Brasil vivenciava a ditadura militar cujas intervenções estavam assentadas em políticas militaristas de retomada do crescimento econômico, orientadas para aberturas ao mercado exterior (em escala menor, ao interno) pela via de criação de leis e de instituições com o objetivo de promover concessões fiscais, econômicas e ambientais para implantação de empreendimentos: a região Amazônica é um exemplo relevante. É nesta ótica que o CIPS surge para o Estado de Pernambuco como salvação aos males econômicos então vivenciados, por conseguinte oferecendo argumentos para (re)entender, a priori, a gênese de Suape: essencialmente econômica e fundamentalmente desintegrado - e, sobretudo, substantivamente desintegrador - da perspectiva ambiental. Desta afirmativa é que resultam precisamente os números percentuais relativamente altos de supressão vegetal mencionados.

Novamente sob a justificativa de utilidade pública e do interesse social, entre 1997 e 2015, o movimento é acelerado em torno da criação de leis visando a autorização de supressão de APPs, predominantemente envolvidas com a implantação e ampliação dos megaempreendimentos (Estaleiros, refinaria, petroquímica, obras de infraestruturas etc.). Autorizações que acabam por evidenciar o Estado, como um agente político altamente determinado a cumprir com êxito o desinderatum econômico (Coelho e Tavares, 2013); na contemporaneidade tão necessitado e orientado a adoção de políticas públicas liberalistas, obviamente de forma idealista. Adiante é apresentado (tabela 1) em detalhes as

Silva, D. N. S., Gomes, E. T. A., Serna, A. G. 
Revista Brasileira de Geografia Física v11, n.03 (2018) 1162-1175.

corporações privadas favorecidas pelas leis autorizativas respaldadas pelo Estado e pela $\mathrm{CPRH}$.

A Tabela 1 consta que, entre 1997 e 2015, foram concedidas pela CPRH autorizações para supressão de 886,7 hectares de APPs para fins de ampliação da Zona Industrial Portuária (ZIP), do Estaleiro Atlântico Sul (EAS), da Refinaria do Nordeste Abreu e Lima (RNEST) e obras de infraestrutura (rodovias, dragagens etc.). Juntas, as empresas RENEST e EAS representam quase a totalidade das supressões autorizadas (considerando a área geográfica para implantação e as obras de construção e pavimentação da rodovia vicinal, trecho: entroncamento da BR 101/Rua Padre Nestor de Alencar - DER).

Adiciona-se a esses valores os manguezais e restingas presentes na ilha de Tatuoca que tiveram a supressão autorizada, entre 2008 e 2015 para ampliação do EAS, implantação do Estaleiro Vard Promar e obras de dragagem para entrada e saída de navios. O montante já supera o que determina a lei Estadual $\mathrm{n}^{\circ}$ 14.046/2010: a supressão total de restingas e de manguezais em até 691 ha para o CIPS até 2020; documento que também, autoriza a urbanização de Tatuoca em sua totalidade. (CPRH, 2010). Sobre as obras para ampliação da ZIP, os 132 ha expostos na tabela apenas representam dados de 1997 a 2008, sugerindo um somatório bem maior, uma vez que dos cerca de 1.000 ha de floresta nativa, em finais da década de 80, 60\% já estavam degradados em decorrência da implantação da ZIP (Braga, Uchoa e Duarte, 1989). Esses fatos são determinantes para que o território de Suape comtemple uma paisagem (figura 1) com notória fragmentação na atualidade.

Não é por acaso que na entrada deste século, a Região Metropolitana do Recife (RMR) apenas concebia cerca de $5 \%$ de manguezais em relação à cobertura original. Como exemplo, a resultante de compensações ambientais pagos pela RNEST, quando considerada a transferência para os manguezais com previsões de serem aterrados para sua instalação ( $1,7 \mathrm{ha})$, o custo inicial estimado apontava para aproximadamente R\$5.324.060 em relação ao ano de 2007 (Ramos, et. al., 2007). Em 2013, o valor compensatório ${ }^{5}$ acabou sendo ampliado para mais R \$ 137 milhões. A imagem infra (figura 2) sintetiza a evolução histórica de uso e ocupação do solo em Suape, em relação aos desflorestamentos de APPs e outros remanescentes florestais.

Os mapas temáticos trabalhados e georreferenciados no software ArcGIS, a partir de imagens coletadas no aplicativo Google Earth Pro, evidenciam os anos de 2016, 2010, 2008 e 1989 escolhidas por serem precisamente nessas décadas quando ocorrem as principais alterações no ambiente em virtude da instalação e ampliação de empreendimentos e do porto propriamente dito, em termos de infraestrutura. Os resultados corroboram com os dados mencionados na tabela 1 e mais adiante, na tabela 2. Os avanços de uso e ocupação do solo para o caso EAS, por exemplo, cujas obras se iniciam em 2007/08 e são ampliadas em 2010 junto a instalação vizinha do Estaleiro Promar em 2013, impactaram a ilha de Tatuoca quase em sua totalidade. A supressão de manguezais e restingas nativos e a expulsão de populações locais estão entre as principais consequências (Coelho e Tavares, 2013).

A técnica é fundamentada na metodologia utilizada pela EMBRAPA demostrando que nas áreas onde ocorreram as transformações (RNEST, EAS, Estaleiro Promar e ZIP Suape), sem exceção, eram constituídas de Mata nativa, com predominância de manguezais, restingas e Mata Atlântica (Embrapa, 2017). Vale reiterar, os manguezais estão ligados à subsistência de várias famílias de pescadores e pescadoras artesanais; e biologicamente servindo como berçário natural para reprodução de muitos espécimes animais, que por sua vez são a base alimentar da atividade de pesca na região (Coelho e Tavares, 2013).

Tabela 1 Empreendimentos e o quantitativo de áreas a serem suprimidas pelas leis autorizativas

${ }^{5}$ A compensação ambiental é um instrumento de proteção
ambiental que se encontra previsto na Lei Federal $\mathrm{n}^{\circ}$
$9.985 / 2000$ e na Lei Estadual $\mathrm{n}^{\circ} 13.787 / 2009$ e pode ser
entendida como um mecanismo financeiro de
responsabilização pelo significativo impacto ambiental

causado ao meio ambiente por determinados empreendimentos (Disponível em: http://www.cprh.pe.gov.br/Unidades_de_Conservacao/co mpensacao_ambiental/41789\%3B81063\%3B5004\%3B0 $\% 3 \mathrm{~B} 0 . \mathrm{asp})$.

Silva, D. N. S., Gomes, E. T. A., Serna, A. G. 
Revista Brasileira de Geografia Física v11, n.03 (2018) 1162-1175.

\begin{tabular}{|c|c|c|c|}
\hline $\begin{array}{c}\text { Lei de } \\
\text { autorizativa/ano }\end{array}$ & Empreendimento a que corresponde & $\begin{array}{l}\text { Área para supressão } \\
\text { Hectare (ha) }\end{array}$ & $\begin{array}{l}\text { No CIPS e } \\
\text { áreas de } \\
\text { influência }\end{array}$ \\
\hline \multirow[t]{3}{*}{$\mathrm{N}^{0} \mathbf{1 1 . 5 1 7 / 1 9 9 7}$} & $\begin{array}{l}\text { Implantação de Projeto de Complementação do Sistema de } \\
\text { Trens Metropolitanos do Recife, nos trechos TIP/Timbi e } \\
\text { Recife/Cajueiro Seco; }\end{array}$ & 0,90 ha de mangue & \\
\hline & $\begin{array}{l}\text { Continuação da implantação da Zona Industrial Portuária } \\
\text { de Suape - SUAPE }\end{array}$ & $\begin{array}{ll}28,1 \text { ha de } & \text { mangue } \\
\text { (regeneração); } 26,3 \text { ha } \\
\text { de } & \text { mangue } \\
\text { (conservado) } & \end{array}$ & $\mathrm{X}$ \\
\hline & $\begin{array}{l}\text { Implantação do Complexo das obras decorrentes da } \\
\text { ampliação da pista do Aeroporto dos Guararapes. }\end{array}$ & 0,2 ha de mangue & \\
\hline TC nº 02/1998 & Implantação da ZIP (Zona Industrial Portuária de SUAPE) & $\begin{array}{l}92,8 \text { ha de mangue; } \\
35,9 \text { ha de restinga }\end{array}$ & $\mathrm{X}$ \\
\hline$N^{\circ} 11.907 / 2000$ & $\begin{array}{l}\text { Implantação de traçado da rodovia denominada Vila } \\
\text { litorânea dos Carneiros - SETUR. }\end{array}$ & 0,5 ha de mangue & \\
\hline TC no 14/2001 & Termo Pernambuco & 3 ha de mangue & $\mathrm{X}$ \\
\hline $\mathbf{N}^{\circ} \mathbf{1 2 . 1 7 7 / 2 0 0 2}$ & $\begin{array}{l}\text { Implantação de traçado da rodovia denominada Vicinal, } \\
\text { entroncamento Rodovia PE-60 (Camela)/ Ponta de } \\
\text { Serrambi - DER. }\end{array}$ & 0,6 ha de mangue & \\
\hline$N^{\circ} \mathbf{1 2 . 4 5 3 / 2 0 0 3}$ & $\begin{array}{l}\text { Implantação e pavimentação da duplicação da rodovia PE- } \\
22 \text {. }\end{array}$ & 1,066 ha de mangue & $\mathrm{X}$ \\
\hline $\mathbf{N}^{\circ} \mathbf{1 2 . 5 0 8 / 2 0 0 3}$ & $\begin{array}{l}\text { Urbanização industrial da Zona Industrial }-03 \text { do } \\
\text { Complexo Industrial Portuário - SUAPE }\end{array}$ & 21,23 ha de & $\mathrm{X}$ \\
\hline $\begin{array}{l}\text { TC n }{ }^{0} 47 / 2004 \\
1^{\circ} \text { TA }\end{array}$ & $\begin{array}{l}\text { Ampliação da ZIP: implantação da fábrica de cerâmica } \\
\text { Monte Carlo }\end{array}$ & $\begin{array}{l}9 \text { ha de Mata Atlântica; } \\
1 \text { ha de mangue }\end{array}$ & $\mathrm{X}$ \\
\hline $\begin{array}{l}N^{\circ} 13.285 / 2007 \text { e } \\
\text { TC no75/2008 }\end{array}$ & $\begin{array}{l}\text { Urbanização industrial da Zona Industrial }-03 \text { do } \\
\text { Complexo Industrial Portuário - SUAPE e Implantação da } \\
\text { Refinaria Abreu e Lima }\end{array}$ & 1,76 ha de mangue & $\mathrm{X}$ \\
\hline$N^{0} 13.557 / 2008$ & $\begin{array}{l}\text { Instalação de moinho de trigo e da unidade industrial } \\
\text { alimentícia de massa; e da dutovia da Refinaria do } \\
\text { Nordeste Abreu e Lima - RNEST, na Zona Industrial } \\
\text { Portuária - SUAPE. }\end{array}$ & 47,3611 ha de mangue & $\mathrm{X}$ \\
\hline$N^{0} 13.615 / 2008$ & $\begin{array}{l}\text { Implantação e pavimentação da rodovia PE-051 e de } \\
\text { pavimentação da ciclovia na rodovia PE-09-SETUR. }\end{array}$ & 2,22 ha de mangue & $\mathrm{X}$ \\
\hline$N^{\circ} 13.637 / 2008$ & $\begin{array}{l}\text { Ampliação de área de implantação do Estaleiro Atlântico } \\
\text { Sul, na Zona Industrial Portuária - SUAPE. }\end{array}$ & $\begin{array}{l}26,8036 \text { ha de mangue; } \\
37 \text { ha de restinga. }\end{array}$ & $\mathrm{X}$ \\
\hline $\mathbf{N}^{\circ} \mathbf{1 3 . 9 2 1 / 2 0 0 9}$ & $\begin{array}{l}\text { Implantação e pavimentação da rodovia vicinal, trecho: } \\
\text { entroncamento da BR 101/Rua Padre Nestor de Alencar - } \\
\text { DER. }\end{array}$ & 1,01 ha de mangue & \\
\hline$N^{\circ} 14.046 / 2010$ & $\begin{array}{l}\text { Implantação e pavimentação da rodovia vicinal, trecho: } \\
\text { entroncamento da BR 101/Rua Padre Nestor de Alencar - } \\
\text { DER, área de influência do Estaleiro Atlântico Sul e a } \\
\text { Refinaria Abreu e Lima. }\end{array}$ & 508,36 ha de mangue & $\mathrm{X}$ \\
\hline$N^{\circ} 14.129 / 2010$ & $\begin{array}{l}\text { Implantação das } 2^{\mathrm{a}} \text { e } 3^{\mathrm{a}} \text { etapas do projeto denominado Via } \\
\text { Mangue - Empresa de Urbanização do Recife. }\end{array}$ & 8,91 ha de mangue & \\
\hline$N^{\circ} 013 / 2013$ & Instalação do Estaleiro Vard Promar & $\begin{array}{l}80 \text { ha (mangues e } \\
\text { restinga) }\end{array}$ & $\mathrm{X}$ \\
\hline$N^{0} 628 / 2015$ & $\begin{array}{l}\text { Dragagem para alargamento do canal marítimo próximo } \\
\text { aos Estaleiros Vard Promar e Atlântico Sul }\end{array}$ & 0,1244 ha de mangue & $\mathrm{X}$ \\
\hline Total & & 907,84 ha & \\
\hline
\end{tabular}

Fonte: CPRH (2017); Coelho e Tavares (2013). (Elaborado pelos autores). 
Revista Brasileira de Geografia Física v11, n.03 (2018) 1162-1175.

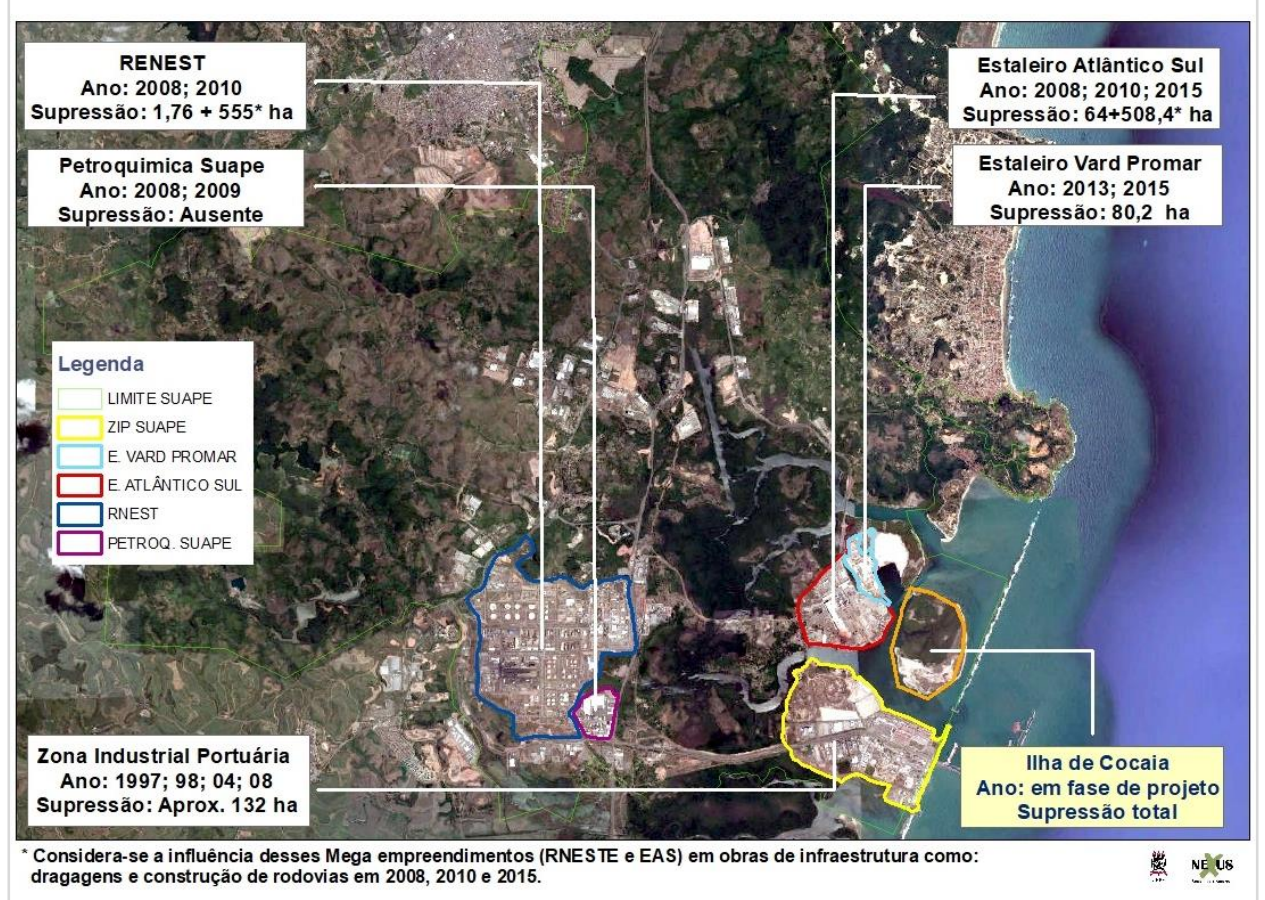

Figura 1. Principais e empreendimentos e obras favorecidas pelas autorizações de supressão, e os respectivos valores. Fonte: CPRH (2017); Coelho e Tavares (2013). (Elaborado pelos autores).
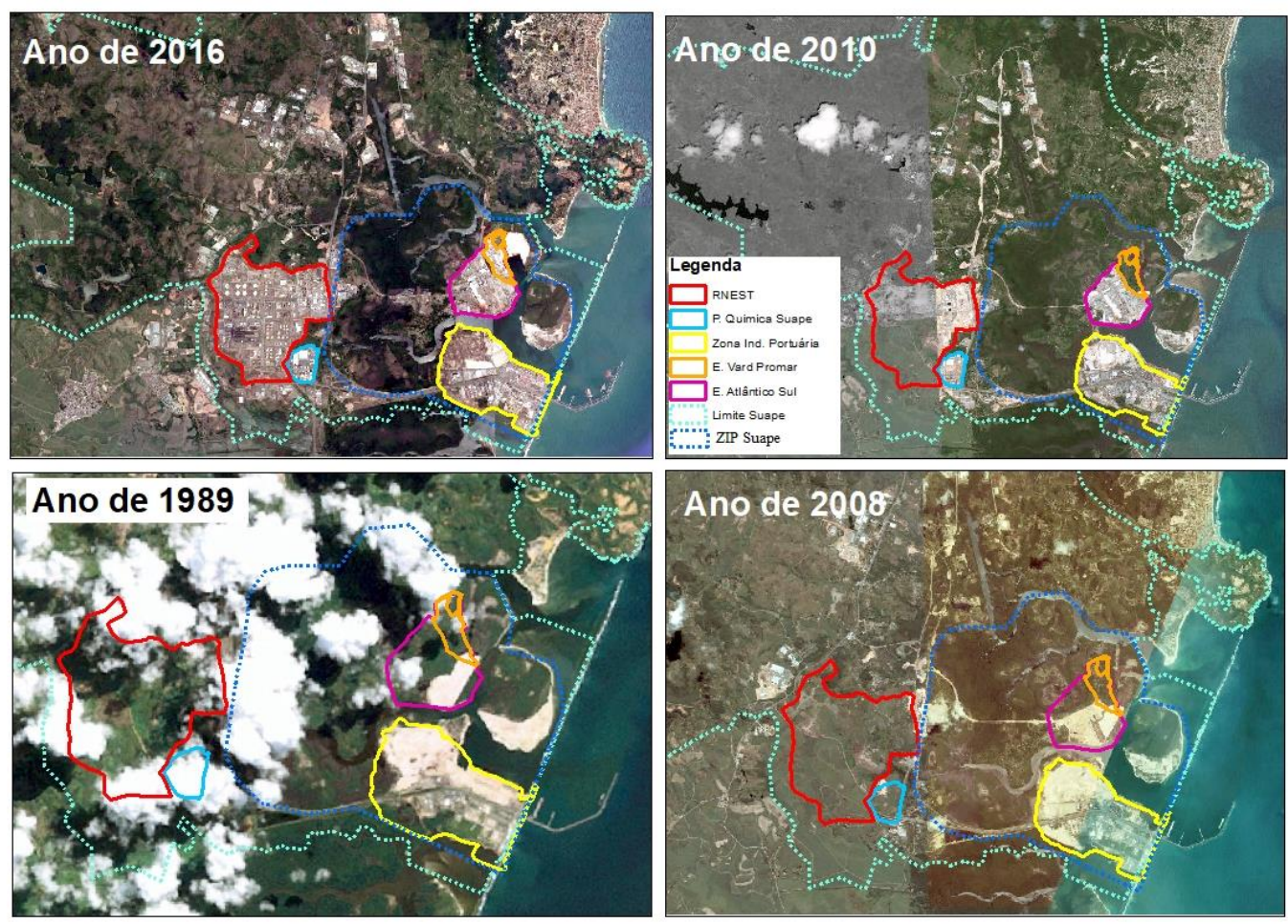

Figura 2 Mapa histórico de uso do solo no território de Suape em relação a supressão de APPs. 
Revista Brasileira de Geografia Física v11, n.03 (2018) 1162-1175.

Sobre a legitimidade dos casos citados é pontuada a necessidade, dispostas nos decretos do Conselho Nacional do Meio Ambiente (CONAMA) de 86/87, de realização de audiências públicas visando a participação da sociedade civil no processo autorizativo de empreendimentos, que em decorrência de sua instalação venham degradar o ambiente de forma moderada e/ou alta. Em Pernambuco a adoção desse instrumento está, sobretudo, a cargo da CPRH.

Em que pese as audiências públicas, os relatórios produzidos pela $\mathrm{CPRH}$, de um lado, apontam com bastante otimismo, para uma crescente realização de audiências públicas no Estado de Pernambuco. Se os números adiante podem ser considerados altos ou não, o fato é que o documento afirma, que entre 1997 e 2006, houve a efetivação de 8 audiências; entre 2007 e 2010, 15 audiências; por fim, o relatório 2011-2014 confirma um aumento do número de audiências para 23 (CPRH, 2015).

De outro, a contradição se instala na medida em que, das 15 audiências públicas concebidas de 2007 a 2010, não há menção aos empreendimentos localizados em Suape; e de 2011 a 2014, apenas uma foi destinada ao Complexo portuário de Suape, especificamente, sobre a instalação do Estaleiro Vard Promar, em 2013. Ao analisar esses relatórios difundidos pela instituição é possível inferir que o CIPS vem atuando num contexto dicotômico e idealista de desenvolvimento, no qual o Estado tem autorizado na esfera do CIPS - legitimado através da CPRH (vale lembrar, órgão ambiental técnicodeliberativo, não administrativo) - a instalação e ampliação de megaempreendimentos com alto impacto ambiental sobre APPs (CPRH, 2015). Autorizações legitimadas com fortes indícios de violações, na medida em que ocorrem sem a participação da sociedade supostamente favorecida.

Portanto, diferentemente do que é divulgado no website oficial da empresa Suape e nos meios de comunicação - a integração social e ambiental do CIPS com a população local -, o CIPS se converte em um enclave geográfico-político-econômico quase e/ou totalmente ilhado da população local, à medida que não participam das decisões, quer de forma consultiva, tampouco (e, menos ainda) deliberativa, como costumam evidenciar os núcleos socioambientais de Suape e a CPRH.

Sobre a CPRH há um outro dado a ser considerado. Por meio de sua Câmara Técnica de Compensação Ambiental, como evidenciado no seu relatório, o órgão negociou recursos da ordem de $\mathrm{R} \$$ 215 milhões em compensação ambiental. Vale ressaltar, que a compensação ambiental como instrumento de proteção ambiental, previsto na Lei Federal $\mathrm{n}^{\circ} 9.985 / 2000$ e na Lei Estadual $\mathrm{n}^{\circ}$ 13.787/2009 é utilizada como um mecanismo financeiro de responsabilização pelo significativo impacto ambiental causados por empreendimentos, identificados no Estudo de Impacto Ambiental e no respectivo Relatório de Impacto Ambiental (EIA/RIMA), e não como um instrumento de legitimação das atividades oriundas dessas empresas.

No site da CPRH constam os acordos formalizados entre o órgão e os empreendimentos, entre os anos de 2005 e 2016, com os seus respectivos valores compensatórios, que segundo a CPRH, são destinados para a manutenção das Unidades de Conservação (UC), podendo inclusive, o beneficiamento ser contemplado com a criação de novas UCs. A relação dos compromissos assumidos e os seus beneficiários são abaixo detalhados (Tabela 2).

Os dados supracitados confirmam que, do total recebido por compensações, aproximadamente R \$ 195 milhões (dos R\$ 215 milhões totais) são resultantes de licenciamentos/autorizações para atividades no Território de Suape, com destaque para as corporações EAS, Petroquímica Suape, RNEST, Estaleiro Promar e obras de infraestrutura (contorno Cabo-Suape). A lei de compensação ambiental, Decreto $\mathrm{N}^{\mathrm{o}} 6.848$, dispõe sobre o cálculo (que varia entre 0 a $5 \%$ de máximo) e o mais importante, como a quantia resultante da compensação deva ser utilizada. Obrigatoriamente, os recursos são para a criação de UCs e a recuperação de áreas degradadas, com a prerrogativa de que os ambientes a serem contemplados, sejam semelhantes e/ou idênticos e estejam próximos aqueles que eventualmente tenham sido impactados. 
Revista Brasileira de Geografia Física v11, n.03 (2018) 1162-1175.

Tabela 2 Relação dos acordos firmados no período de 2005 a 2016, mostrando os empreendimentos envolvidos, sua localização e os valores correspondentes.

\begin{tabular}{ccc}
\hline $\begin{array}{c}\text { No Termo de } \\
\text { Compromisso }(\text { TC) }\end{array}$ & Empreendimento & $\begin{array}{c}\text { Valor da Compensação } \\
\text { Ambiental (R\$) }\end{array}$ \\
\hline TC 066/2005 & Estaleiro Atlântico Sul - EAS & $4.498 .697,70$ \\
TC 001/2006 & Aterro Muribeca S/A Paulista & $24.288,94$ \\
\hline TC 002/2006 & Fábrica de PTA - MGBRBA & $5.550 .000,00$ \\
\hline TC 050/2007 & Petroquímica Suape & $5.880 .696,01$ \\
\hline TC 067/2008 & PE 51 - SETUR & $251.000,00$ \\
\hline TC 001/2013 & Barragem Morojozinho - COMPESA & $110.805,88$ \\
\hline TC 002/2013 & ETE Paiva - COMPESA & $224.637,59$ \\
\hline TC 005/2013 & Barragem Engenho Maranhão - & $813.630,86$ \\
\hline TC 006/2013 & COMPESA & $742.452,34$ \\
\hline TC 007/2013 & Barragem Engenho Pereira - COMPESA & $20.000 .000,00$ \\
\hline TC 012/2013 & Fábrica da FIAT & $137.421 .489,00$ \\
\hline TC 013/2013 & Refinaria Abreu e Lima - RNEST & $1.051 .955,22$ \\
\hline TC 014/2013 & Estaleiro Vard Promar & $35.849,52$ \\
\hline TC 022/2013 & CTR Petrolina & $3.080 .050,48$ \\
\hline TC 035/2013 & TERMOPE & $1.061 .030,28$ \\
\hline TC 001/2014 & Contorno do Cabo - SUAPE & $11.740 .360,18$ \\
\hline TC 006/2014 & Petroquímica Suape & $40.420,15$ \\
\hline TC 001/2015 & CTR Ipojuca - ECOPESA & $6.384 .996,34$ \\
\hline TC 002/2015 & Ramal do Agreste - Ministério da \\
\hline TC 003/2015 & Integração Nacional & $1.014 .918,77$ \\
\hline TC 059/2016 & Navegabilidade - SECID & $293.638,10$ \\
\hline Total & CTR Candeias - ECOPESA Ambiental & $73.061,28$ \\
\hline & CTR Caruaru - EMPESA & 215 milhões \\
\hline
\end{tabular}

Ocorre que as leis autorizativas permitiram a supressão de APPs - para o caso do CIPS, a maioria delas vinculadas a supressão de ecossistemas de manguezal - portanto, os ambientes a serem contemplados deveriam ser iguais ou semelhantes, especialmente, pelo seu grau de importância. Como de costume, a teoria não vem seguindo a regra. Das 12 UCs criadas pela CPRH entre 2011 e 2014, 6 delas são para ambientes de mata atlântica e outras 6 para Caatinga, dentre as quais apenas uma está relacionada com o CIPS: a Estação ecológica de Bita e Utinga (mata atlântica, 2.467,10 ha, criada em 2012). Estrategicamente foi criada nas proximidades do CIPS a Área de Relevante Interesse Ecológico (ARIE) dos Rios Ipojuca-Merepe (Manguezal e Restinga, 1.488,81 ha, criada em 2014), situada no município de Ipojuca (Suape, 2016), atualmente com ausência de órgãos gestores e de manejo etc.
No relatório também constam os valores médios para criação de uma UC, aproximadamente R \$ 3,5 milhões. Na Estação ecológica de Bita e Utinga, por exemplo, o Estado já utilizou (e, ainda continua a gastar) $\mathrm{R} \$ 42$ milhões (em especial, para "reassentamentos" de famílias). Montante retirado dos 137 milhões oriundos da compensação ambiental pagos pela RNEST, valores que não chegam perto da totalidade econômica (R $\$ 215$ milhões) recebida pelo Estado, mas que, se revelam altos para criação da UC (Araújo, 2016).

Esse movimento ao que parece caminha paradoxalmente aos imperativos de conservação ou preservação ambiental com o respeito social (tão bem representados no discurso informacional dos agentes governamentais), à medida que se utiliza do álibi ambiental de forma a objetivar - através de processos de desterritorializações por espoliação de populações locais e consecutivamente com a apropriação do 
Revista Brasileira de Geografia Física v11, n.03 (2018) 1162-1175.

território - precisamente a proteção (no sentido de dominação) do território.

Em razão disso, questiona-se o destino dado pelo Estado ao montante recebido. Os R $\$ 215$ milhões veiculados como um ganho socioambiental, como assinalam Coelho e Tavares (2013) são na realidade a venda do direito de poluir e degradar, na medida em que "A compensação ambiental busca um ajustamento das atividades discordantes e não, obviamente, viabilizar os "desejos poluidores" do empreendedor" (p. 6). Salienta-se ainda, que para a ARIE dos rios Ipojuca-Merepe, são também questionáveis os critérios de sua criação, uma vez que os manguezais, enquanto APPs, já são protegidos por lei federal, logo, não necessitando torna-se UC, ou seja, cria-se proteção para o que já é protegido por lei.

Adicionalmente o Estado de Pernambuco, contempla a celebração de licenciamentos de forma online - em seu sistema de licenciamento ambiental eletrônico SILIAWeb, com fundamento no art. 11, $\S 3^{\circ}$ da Lei Estadual 14.249/2010 - de um total de 25.326 (vinte e cinco mil trezentos e vinte e seis) licenças entre 2011 e 2014; e 1244 no ano de 2015 para empreendimentos localizados em todo o Estado de Pernambuco, valor correspondente a média aproximada de 20 licenças emitidas por dia; números comemorados pelos gestores e técnicos, justificados pela diminuição no custo de processos licitatórios (CPRH, 2014; CPRH, 2015), em outros termos, autorizações sem qualquer tipo de fiscalização presencial.

O último Plano Diretor do CIPS, formalizado em 2011, intitulado "Novo Plano Diretor - Suape 2030 ” traz afirmações no mínimo questionáveis, uma vez que muitas áreas ditas de preservação, ou seja, dentro do perímetro atual dos 59\% de áreas preservadas pelo complexo industrial, as chamadas zonas de preservação ecológica (ZPEC), constituídas de remanescentes de mata atlântica e de manguezais, são áreas consideradas como exclusiva e "eminentemente de estoque para compensações ambientais" (Suape, 2011, p. 43). Ou seja, áreas intencionalmente salvaguardadas para justificar os presumíveis impactos ambientais futuros no CIPS. Por exemplo, já está previsto no plano diretor que os manguezais e estuários presentes em Suape, com exceção daqueles inseridos na UC Engenho da Ilha, poderão ser suprimidos para fins econômicos, quando em caso de interesse social ou utilidade pública, revelando a implícita intencionalidade do discurso de ampliação de $48 \%$ para $59 \%$ de preservação. Quando na verdade essas áreas serão utilizadas como objeto de compensação, uma forma teórica de autorização do direito de degradar aos agentes econômicos. Como se não bastasse a grande gama de incentivos econômicos e ficais que já os beneficiam...

Também não fica claro a contemplação ambiental junto a necessidade de processos de desterritorializações por espoliação, uma vez que se prevê para essas áreas o princípio da "transitoriedade" aos posseiros residentes, que significa nada mais que a retirada de populações locais em tempo determinado pelos agentes políticos de Suape; os quais são vistos como um problema (os $\mathrm{R} \$ 42$ milhões gastos para retirada dos posseiros na UC supramencionada é um exemplo). De forma literal o documento revela que "a gradativa remoção das populações que hoje moram na ZPEC é de fundamental importância...” (Suape, 2011, p. 80), caracterizando a intencionalidade de um Estado, atuante e intervencionista sobre questões de luta pela terra. Como afirma o Fórum Suape, atuando como um segregador socioespacial, inclusive se utilizando de meios, diga-se, nada formais (porém muito usuais): o uso da força para expulsar muitos cidadãos de suas moradias (Fórum Suape, 2017).

A própria construção e aprovação do atual plano diretor, Suape 2030, entende-se ser constituída de um viés arbitrário, pois contempla em sua estrutura, majoritariamente intencionalidades vinculadas aos agentes políticos e econômicos, uma vez que quem assina o documento são os gestores (o então Governador Eduardo Campos, seu secretário de desenvolvimento econômico, Geraldo Júlio; o presidente de Suape e diretores financeiros, urbano e patrimoniais), portanto, sem a devida participação da sociedade civil nos processos decisórios, principalmente a população local diretamente afetada e, reitera-se, supostamente beneficiadas das consequentes objetividades dessas decisões.

\section{Conclusões}

Em que pese a legislação ambiental brasileira que dispõem sobre APPs, e ainda, a jugar pela teoria descrita nos documentos formulados (decretos e/ou códigos florestais) não há dúvidas de 
Revista Brasileira de Geografia Física v11, n.03 (2018) 1162-1175.

o que se deve, como e a quem são, em termos legais, as responsabilidades de proteger, deliberar e aplicar as disposições rumo à preservação e conservação ambiental. Para o caso de Suape, a sua configuração territorial é repleta de atributos que reclamam a aplicabilidade das leis de que tratam de APPs, tendo em vista a presença de recursos hídricos protegidos por vegetação e ecossistemas típicos, como os manguezais, restingas, resquícios de mata atlântica e áreas estuarinas. Portanto, teoricamente, sugerindo um ambiente preservado e/ou com uma relação entre sociedade e natureza dotada de práticas sustentáveis.

Entretanto, o movimento histórico em torno do Complexo Industrial Portuário (CIP) instalado, como evidenciado, é contraditório. Fundamentado em ideologias políticas de desenvolvimento compromissadas com imperativos econômicos, os agentes com atuação no CIPS têm se utilizado de estratégias (políticas públicas) autorizativas que acabam por (des)legitimar as prerrogativas definidas nas leis ambientais - também por meio da criação de leis. Os dados coletados e as imagens georreferenciadas autorizam essa assertiva. Peculiaridade e prática legitimadas por argumentos de exceção de utilidade pública e interesse social utilizados com regra geral, cuja consequência vem sendo a supressão de vastíssimas áreas de vegetação permanente e consecutivamente degradações socioambientais que têm alterado de forma negativa o cotidiano de populações, em especial, famílias de pescadores e pescadoras artesanais.

Outrossim, é preciso repensar as estratégias historicamente adotadas pelos órgãos ambientais, em especial a CPRH, que veicula com bastante otimismo os índices econômicos alcançados das compensações ambientais, uma vez que sua adoção vem sendo construída em meio a violações sociais e ambientais. A lei compensatória não é concebida com a prerrogativa de proteger o agente causador ou até mesmo dar o direito de degradar, mas sim, de preservar e/ou conservar a natureza promovendo socialmente as populações que dela dependem. Os termos ambientais e autorizações ditos menos burocratizados também são contraditórios aos imperativos socioambientais requeridos na contemporaneidade, ensejando a sua revisão emergencial. Além disso, também nos parece emergencial a fiscalização e revisão do atual plano diretor, no que se refere aos critérios para criação das ZPECs, em especial, a UC de Bita e Utinga cujo valor gasto se mostra alto $\mathrm{e}$ orientado não para conservação, mas sim, para retirada de famílias locais notadamente sob critérios duvidosos e violações aparentes. Assim, as advertências de Santos, (2010) configuram como algo atual, à medida que as responsabilidades socioambientais "assumidas" pela empresa Suape em seu website oficial, se convertem como mais uma estratégia pela qual as "técnicas da informação (por enquanto) são apropriadas por alguns Estados e por algumas empresas, aprofundando assim os processos de criação de desigualdades" (Santos, 2010, p. 39) no campo da materialidade.

A perspectiva de desenvolvimento econômico com sustentabilidade para com as atividades realizadas pelo CIPS no território de Suape, por todo o exposto, se nos apresenta contraditória e ao mesmo tempo desafiadora - no sentido do enfretamento ao que se diz, na teoria, e ao que se quer dizer, na prática. Os resultados demonstram que os rumos político-governamentais orientados para o CIPS têm materializado precarizações ambientais e sociais, logo, apresentando incoerência entre a teoria (documentos, propagandas em seu website oficial etc.) e práxis. Pois, não é suficientemente aceitável que os números econômicos tão difundidos pelos agentes governamentais oriundos das atividades do CIPS, convivam diametralmente com as prerrogativas dispostas nos inúmeros dispositivos legais em suas diversas escalas. Finalmente, o comportamento sustentável apenas teleológico difundido pelos agentes públicos e privados acerca de Suape demonstra que o ideal de sustentabilidade para as atividades econômicas contemporâneas precisam ser apreendias com o rigor necessário, e ademais com suficiente exemplos práticos; a fim de que o campo das subjetividades não se sobreponha aos da materialidade, logo, práxis sustentáveis como regra e não como exceções. Talvez, a reflexão final seja perguntar se há lugar no capitalismo contemporâneo para as práticas sustentáveis como requerem os escritos rumo ao tão "sonhado" desenvolvimento sustentável.

\section{Agradecimentos}

Esta investigação é resultado da colaboração do Programa de Pós-graduação em Desenvolvimento 
Revista Brasileira de Geografia Física v11, n.03 (2018) 1162-1175.

e Meio Ambiente - PRODEMA (UFPE) e do Grupo de Pesquisa sociedade e Natureza Nexus (UFPE).

\section{Referencias}

Araújo, M. P., 2016. A Implantação da Unidade de Conservação Estação Ecológica Bita e Utinga da Refinaria Abreu e Lima, no Porto de Suape - PE. Dissertação (Mestrado). Recife, Faculdade de Ciências da Administração de Pernambuco.

Bakhtin, M., 2010. Marxismo e Filosofia da Linguagem: problemas do Método sociológico na Ciência da Linguagem, $14^{\mathrm{a}}$ ed. HUCITEC, São Paulo.

Braga, R. A. P.; Uchoa, T. M. M.; Duarte, M. T. M. B. 1989. Impactos ambientais sobre o manguezal de Suape - PE. Acta Botanica Brasilica [online] $3 . \quad$ Disponível: http://dx.doi.org/10.1590/S010233061989000300003. Acesso: 15 dez. 2017.

BRASIL, 2016. Constituição Federal de 1988: artigo 225.

Canestrini, V. G., 2012. A revogação da Resolução do CONAMA n. 369 de 28 de março de 2006 com a vigência do Novo Código Florestal - Lei 12.651/2012. Revista Grupo Nacional de Membros do Ministério Público [online] 2. Disponível:

http://www.gnmp.com.br/publicacao/284/arevogacao-da-resolucao-do-conama-n-369-de28-de-marco-de-2006-com-a-vigencia-do-novocodigo-florestal-lei-12-651-2012. Acesso: 16 nov. 2017.

Cavalcanti, H.; Rocha, D., 2015. Nordestes Emergentes. Uma "Expedição Fotográfica" no "Admirável Mundo Novo": O Complexo Industrial Portuário de Suape. RCP, Recife.

Cavedon, F. S.; Vieira, R. S.; Diehl, F. P., 2011., . Regime jurídico das áreas de preservação permanente e desenvolvimento econômico: conciliação ou flexibilização? Ambiente Legal [online] 4.4 Disponível: http://ambientallegal.com.br/. Acesso: 02 nov. 2017.

Coelho, C.; Tavares, P. F., 2013. Uma Abordagem sobre a Perda de Áreas de Manguezal pelas Leis Autorizativas no Estado De Pernambuco. IBEAS - Instituto Brasileiro de Estudos Ambientais, Salvador - Bahia.

CPRH. Agencia Estadual de Meio Ambiente, 2017. Procedimentos para a Audiência pública.
Disponível em: http://www.cprh.pe.gov.br/licenciamento/avaliac ao_impacto_ambiental/participacao_publica/proc edimentos_para_audiencia_publica/39742\%3b35 251\%3b15051819\%3b0\%3b0.asp. Acesso: 10 out. 2017.

CPRH. Agencia Estadual de Meio Ambiente, 2017. Compensação Ambiental. Disponível: http://www.cprh.pe.gov.br/Unidades_de_Conser vacao/compensacao_ambiental/41789\%3B81063 \%3B5004\%3B0\%3B0.asp. Acesso: 10 out. 2017.

CPRH. Agencia Estadual de Meio Ambiente, 2015. Licenciamento Ambiental. Disponível em: http://www.cprh.pe.gov.br/Controle_Ambiental/1 icenciamento/41786\%3B41561\%3B4801\%3B0 \%3B0.asp. Acesso: 10 out. 2017.

CPRH. Agencia Estadual de Meio Ambiente, 2010. Resolução Consema n. 03/2010. Disponível http://www.cprh.pe.gov.br/ARQUIVOS_ANEX O/Resolu\%C3\%A7\%C3\%A3o\%20Consema\%20 003\%20de\%202010;141819;20100817.pdf.

Acesso: 13 ago. 2017.

CPRH. Agencia Estadual de Meio Ambiente, 2010. Rima Complementar: Estaleiro Promar. Disponível em: http://www.cprh.pe.gov.br/downloads/RIMA_P ROMAR_21_11_10.pdf. Acesso: 13 ago. 2017.

EMBRAPA. Empresa Brasileira de Pesquisa Agropecuária, 2017. Zoneamento Agroecológico do Estado de Pernambuco - ZAPE. Disponível: http://www.uep.cnps.embrapa.br/zape/index.php ?link=sobre. Acesso: 13 ago. 2017.

Fórum Suape. Espaço Socioambiental, 2017. Página: Artigos. http://forumsuape.ning.com/page/artigos.

Acesso: 10 dez. 2017.

Gumiero, R. G., 2016. Origem do Complexo Industrial Portuário Suape e os seus Momentos de Implementação (1955-2014). Disponível: https://s3.amazonaws.com/acadex.articles/Article s/56dce806bd82036709a13c1f-fileIdentified.pdf. Acesso: 20 jul. 2017.

Lessa, S., 2013. Capital e Estado de Bem-estar: O caráter de Classe das políticas públicas, $1^{\mathrm{a}} \mathrm{ed}$. Instituto Lukács, São Paulo.

Mészáros, I., 2011. Para além do Capital. Para além do capital: rumo a uma teoria da transição, $1^{\mathrm{a}} \mathrm{ed}$. Boitempo, São Paulo.

MMA. Ministério do Meio Ambiente, 2016. Dispositivos que tratam de Áreas de Preservação

Silva, D. N. S., Gomes, E. T. A., Serna, A. G. 
Revista Brasileira de Geografia Física v11, n.03 (2018) 1162-1175.

Permanente (APP) na legislação brasileira vigente. Ministério do meio ambiente. Brasília.

ONUBR. Noções Unidas Brasil, 2017. Transformando Nosso Mundo: A Agenda 2030 para o Desenvolvimento Sustentável. Disponível: https://nacoesunidas.org/pos2015/agenda2030/. Acesso: 10 set. 2017.

Paniago, M. C. S., 2005. Estado e Capital, em Mészáros: relação de autonomia ou de complemento? II Jornada Internacional de Políticas Públicas. UFAL, São Luís.

Pinheiro, M. V. A. et al., 2013. Dunas móveis: Áreas de Preservação Permanente?. Revista Soc. \& Nat., Uberlândia [online] 25. Disponível: http://www.seer.ufu.br/index.php/sociedadenatur eza/article/view/21010. Acesso em: 15 dez. 2017.

Ramos, M. H. A.; et. al., 2007. A implantação de uma refinaria de petróleo em SUAPE-PE: Uma avaliação dos impactos sócio-econômicoambientais a partir da interpretação de Agendas 21 Locais. In: "VII Encontro da Sociedade Brasileira de Economia Ecológica". Fortaleza.

Santos, M., 2010. Por uma Outra Globalização: do pensamento único à consciência universal, 10. ed. Record, Rio de Janeiro.

Senado Federal, 2012. Código Florestal, Lei federal 12651 de $2012 . \quad$ Disponível: http://www.planalto.gov.br/ccivil_03/_ato20112014/2012/lei/112651.htm. Acesso: 10 jul. 2017.

Senado Federal, 2016. Exposição de Motivos No 29 65, do Ministro da Agricultura. Disponível: http://www2.camara.leg.br/legin/fed/lei/19601969/lei-4771-15-setembro-1965-369026exposicaodemotivos-149358-pl.html. Acesso: 15 jul. 2017.

Silva, V. C. B.; Machado, P. S., 2010. Iniciando o ArcGIS. Curso de Geografia e análise Ambiental. Uni-BH, Belo Horizonte. Disponível: https://unibhgeografia.files.wordpress.com/2011/ 04/apostila-arcgis-prof-patricia.pdf. Acesso: 10 jul. 2017.

SUAPE. Complexo Industrial Portuário, 2011. Novo Plano Diretor Suape 2030. Disponível: http://www.suape.pe.gov.br/images/institucional/ plano_diretor/P14-Plano_Diretor.pdf. Acesso: 12 jul. 2017.

SUAPE. Complexo Industrial Portuário, 2016. Gestão Ambiental: Unidades de Conservação. Disponível: http://www.suape.pe.gov.br/pt/meioambiente/gestao-ambiental/unidades-deconservacao. Acesso: 10 nov. 2017.

SUAPE. Complexo Industrial Portuário, 2016. Desenvolvimento com Responsabilidade. Disponível: http://www.suape.pe.gov.br/pt/meioambiente/desenvolvimento-comsustentabilidade. Acesso: 10 jul. 2017.

SUAPE. Complexo Industrial Portuário, 2017. Suape registra em outubro melhor movimentação mensal de sua história. Disponível: http://www.suape.pe.gov.br/pt/noticias/8noticias/1062-suape-registra-em-outubromelhor-movimentacao-mensal-de-sua-histori. Acesso: 02 nov. 2017. 